\title{
Landscape Dynamics in Hulunbuir Grassland of China
}

\author{
Zhiliang Wang \\ Northeast Institute of Geography and Agroecology, \\ Chinese Academy of Sciences \\ Changchun, China \\ University of Chinese Academy of Sciences \\ Beijing, China \\ College of Science of Qiqihar University \\ Qiqihar, China
}

\author{
Zongming Wang, Bai Zhang, Chunyan Lu, Chunying \\ Ren
}

Northeast Institute of Geography and Agroecology Chinese Academy of Sciences Changchun, China

University of Chinese Academy of Sciences

Beijing, China
Abstract-Hulunbuir Grassland is one of the world famous steppe. Along with global climate change, the beautiful mosaic landscape of grassland-wetland-desert is getting unstable under huge demographic and economic growth pressures. From 2000 to 2010 , the total area of water reduced by $396.52 \mathrm{~km}^{2}$, grassland by $234.71 \mathrm{~km}^{2}$ and forest $146.86 \mathrm{~km}^{2}$, whereas, the areas of construction land, desert, cropland and wetland increased by $462.59 \mathrm{~km}^{2}, 189.43 \mathrm{~km}^{2}, 99.33 \mathrm{~km}^{2}$ and $26.74 \mathrm{~km}^{2}$ respectively. The NP (Number of Patches) increased by 1161 and PD (Patch Density) by 0.02, while the MPS (Mean Patch Size) decreased by $2.24 \mathrm{~km}^{2}$ and LPI (Largest Patch Index) by 0.35 . Moreover, SHDI (Shannon's Diversity Index) and SHEI (Shannon's Evenness Index) increased by 0.02 and 0.10 . These results indicate obviously a process of grassland loss and fragmentation. Although many environmental protection efforts have been carried out from 2000, the degradation trend still can't be hold back.

Index Terms - Landscape Pattern, remote sensing, Hulunbuir Grassland.

\section{INTRODUCTION}

Hulunbuir Grassland, which belongs to Hulunbuir League of Inner Mongolia Autonomous Region, locates in the northeast of Mongolia Plateau and the west of Daxinganling Mountain. As a part of Eurasian Steppe Region, it is a world famous steppe, there are many different and beautiful landscapes, such as huge lake, grassland and wetland. It used to be the best steppe in China, but along with global climate change, the mosaic landscape of grassland-wetland-desert is getting unstable under the huge demographic and economic growth pressures.

Many researchers have investigated the land use/land cover of Hulunbuir League based on RS and GIS, Wang (1999) investigated the quantitive changes of agricultural land use from 1986 to $1996^{[1]}$. Liu and Lu (2008) analyzed spatial and temporal landscape dynamics in the Hulunbuir Forest-steppe Ecotone from 1988 to $2004^{[2,3]}$. Zhang (2009) took Hailaer area as an example to study the spatial-temporal changes of landscape patterns from 1986 to $2001^{[4]}$. Guo (2009) focused on the variation of aeolian desertified land from 1984 to $2000^{[5]}$ and zhang (2010) focused on the spatial and temporal dynamic of vegetation cover in the Hulunbuir Grassland from 1998 to $2008{ }^{[6]}$. However, these researchers mainly focused on the land use/land cover of the whole Hulunbuir League, or analyzed the desertification of Hulunbuir Grassland only. None has taken Hulunbuir Grassland as a study area to analyze its landscape patterns and driving forces until now.

This paper aimed to analyze the spatial-temporal dynamic changes of landscape pattern of Hulunbuir grasslands by interpreting two-period Landsat-5 TM images of 2000 and 2010.

\section{STUDY AREA AND METHOD}

\subsection{Study area}

Hulunbuir Grassland is located between $47^{\circ} 20^{\prime}-50^{\circ} 15^{\prime} \mathrm{N}$ and $115^{\circ} 30^{\prime}-121^{\circ} 10^{\prime} \mathrm{E}$, with a total area of $8.36 \times 10^{4} \mathrm{~km}^{2}$.

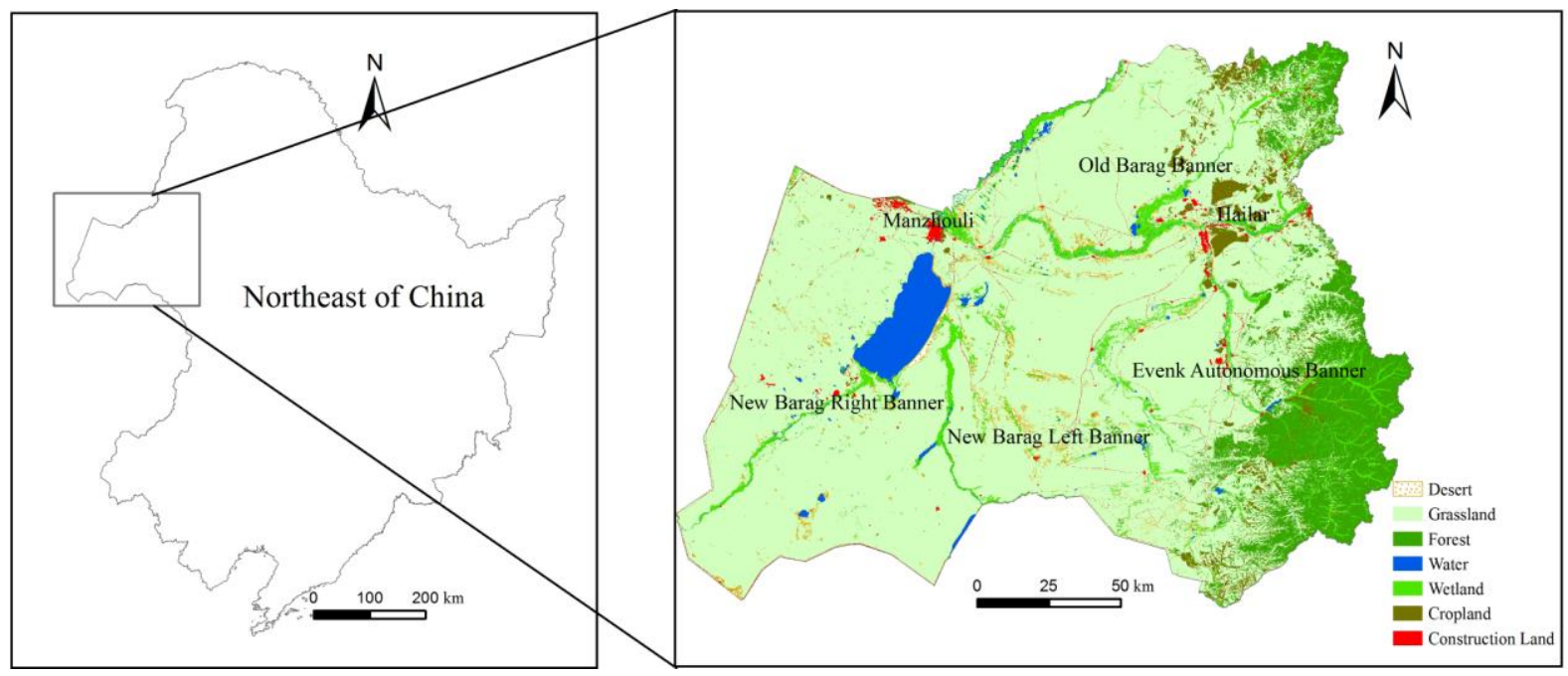

Fig.1. Location Map of Hulunbuir Grassland. 
Hulunbuir Grassland is a flat, vast and undulating high plain with elevation of 600-750 m above sea level ${ }^{[8]}$. The study area belongs to the temperate continental monsoon climate, which is mild and short in summer, cold and long in winter. The averaged annual temperature varies from 0 to $3{ }^{\circ} \mathrm{C}$, Frost-free period ranges from 85 to 155 days. Mean annual precipitation is $250-350 \mathrm{~mm}{ }^{[9]}$, but it is uneven in the spatial and temporal distribution. It decreases from the northeast to the southwest and about $80 \%$ concentrates between June and September. Grassland vegetation is regularly distributed across forest steppe, meadow steppe and arid steppe from east to west. The eastern area belongs to the forest-steppe transition zone and the other area is mostly natural grasslands ${ }^{[7]}$.

\subsection{Method}

\subsubsection{Data collection and process of remote sensing images}

To explore the landscape changes of the grassland from 2000 to 2010, 9 scenes of Landsat-5 TM (July to September) each year were obtained. The mosaic images were interpreted by Ecognition8.64 software. The landscape types were classified into 7 categories including grassland, forest, wetland, water (lake, river), cropland, desert and construction land (residential, traffic and industrial land). The data format is ESRI shape file (vector). The accuracy was assessed by field survey when spatial sites (GPS Point), land cover types and environment descriptions were recorded. We built up a field survey database and imported it to ArcGIS9.3 in order to verify land cover data.

\subsubsection{Indices of landscape patterns}

Spatial change of landscape patterns was analyzed by FRAGSTATS3.3 software, computing the landscape indices of land cover shape file which have been interpreted already. Firstly, land cover shape file in different periods were converted to GRID format. Then, we selected several landscape indices on landscape level which can reveal the spatial pattern of patch changes, including Number of Patches (NP), Patch Density (PD), Mean Patch Size (MPS), Largest Patch Index(LPI), Landscape Shape Index (LSI), Shannon's Diversity Index (SHDI) and Shannon's Evenness Index (SHEI) [10].

\subsubsection{Centroids of landscape types}

The movement of centroids could indicate the dynamic changes of landscape patterns obviously. So, we calculate the mean coordinates of each landscape type as its centroid, then add the coordinates of the centroid into the attribute table of landscape patterns, finnally the movement of centroid could be obtained by analysis tools of ArcGIS9.3.

\section{RESULTS}

\subsection{Changes in landscape structure}

From the tables below, we could get that the areas of water, grassland and forest decreased largely from 2000 to 2010 . The total area of water decreased by $13.79 \%$ about $396.52 \mathrm{~km}^{2}$, just the Hulun Lake decreased by $362.09 \mathrm{~km}^{2}$ which account for $91.32 \%$. The grassland decreased by $0.37 \%$ about $234.71 \mathrm{~km}^{2}$ and forest by $1.73 \%$ about $146.86 \mathrm{~km}^{2}$, whereas, the area of construction land, desert, cropland and wetland increased by $462.59 \mathrm{~km}^{2}, 189.43 \mathrm{~km}^{2}, 99.33 \mathrm{~km}^{2}$ and $26.74 \mathrm{~km}^{2}$ respectively. In short, large area of grassland and forest, as the main landscapes, were transformed to construction land, cropland and desert from 2000 to 2010.

Table 1 The Conversion Matrix Table of Landscape Types $\left(\mathrm{km}^{2}\right)$

\begin{tabular}{|c|c|c|c|c|c|c|c|c|}
\hline Landscape Types & Grassland & Cropland & Construction Land & Forest & Desert & Wetland & Water & Total (2000) \\
\hline Grassland & 62750.43 & 164.92 & 401.77 & 9.83 & 241.50 & 216.26 & 97.15 & 63881.86 \\
\hline Cropland & 70.31 & 2182.46 & 35.03 & 0.49 & 3.39 & 1.57 & 1.66 & 2294.92 \\
\hline Construction Land & 4.59 & 0.10 & 508.19 & 0.29 & 0.02 & 0.18 & 0.08 & 513.45 \\
\hline Forest & 106.65 & 31.41 & 14.20 & 8340.00 & 0.51 & 7.10 & 1.03 & 8500.90 \\
\hline Desert & 184.02 & 0.11 & 4.44 & 1.20 & 748.58 & 9.71 & 6.34 & 954.40 \\
\hline Wetland & 211.29 & 14.86 & 10.31 & 2.16 & 21.96 & 4132.33 & 108.99 & 4501.90 \\
\hline Water & 319.86 & 0.38 & 2.09 & 0.07 & 127.87 & 161.50 & 2263.03 & 2874.80 \\
\hline Total (2010) & 63647.15 & 2394.25 & 976.03 & 8354.04 & 1143.83 & 4528.65 & 2478.28 & 83522.22 \\
\hline
\end{tabular}

Table 2 Changes of Landscape Type Area from 2000 to $2010\left(\mathrm{~km}^{2}\right)$

\begin{tabular}{|c|c|c|c|c|}
\hline Landscape Types & Area of 2000 & Area of 2010 & Changes of Area & Change Rate (\%) \\
\hline Grassland & 63881.86 & 63647.15 & -234.71 & -0.37 \\
\hline Cropland & 2294.92 & 2394.25 & 99.33 & 4.33 \\
\hline Construction Land & 513.45 & 976.03 & 462.59 & 90.09 \\
\hline Forest & 8500.90 & 8354.04 & -146.86 & -1.73 \\
\hline Desert & 954.40 & 1143.83 & 189.43 & 19.85 \\
\hline Wetland & 4501.90 & 4528.65 & 26.74 & 0.59 \\
\hline Water & 2874.80 & 2478.28 & -396.52 & -13.79 \\
\hline
\end{tabular}




\subsection{Changes of indices}

The Landscape indices, NP grew 1161 from 65315 (2000) to 66476 (2010) and PD increased by 0.02, while MPS decreased by $2.24 \mathrm{~km}^{2}$ from $127.88 \mathrm{~km}^{2}$ (2000) to $125.64 \mathrm{~km}^{2}$ (2010) and LPI decreased by 0.35. Moreover, SHDI grew 0.02 from 0.95 (2000) to 0.97 (2010) and SHEI grew 0.10 from 0.49 (2000) to 0.50 (2010). This means, the fragmentation of grassland hasn't been hold back till 2010, though many environmental protection strategies have been carried out from 2000 .

Table 3 Landscape Index of Hulunbuir Grassland

\begin{tabular}{|l|l|l|l|l|l|l|l|}
\hline Index & NP & PD & MPS & LPI & LSI & SHDI & SHEI \\
\hline 2000 & 65315 & 0.78 & 127.88 & 58.66 & 85.13 & 0.95 & 0.49 \\
\hline 2010 & 66476 & 0.80 & 125.64 & 58.31 & 90.21 & 0.97 & 0.50 \\
\hline
\end{tabular}

\subsection{Movement of centroid}

From Fig. 2, we could find that the centroids of grassland, forest, desert and cropland all moved to the southeast from 2000 to 2010, the centroid of cropland moved about $39.24 \mathrm{~km}$, the grassland $30.32 \mathrm{~km}$, desert $23.80 \mathrm{~km}$ and forest $3.49 \mathrm{~km}$. The movement of centroids indicates that the southeast forest line of Hulunbuir Grassland retracted and the area of cut forest may become grassland or cropland. So, the centroids of grassland and cropland move together with the centroid of forest to the southeast.

While, to the movement of centroid of desert, the southern desert belt from Ganzhuer Temple of Amugulang Town to the west of Huihe River, where dunes become active and larger in recent 30 years $^{[11]}$, may be the reason why the centroid of sandland moved to the southeast about $23.80 \mathrm{~km}$ from 2000 to 2010 .

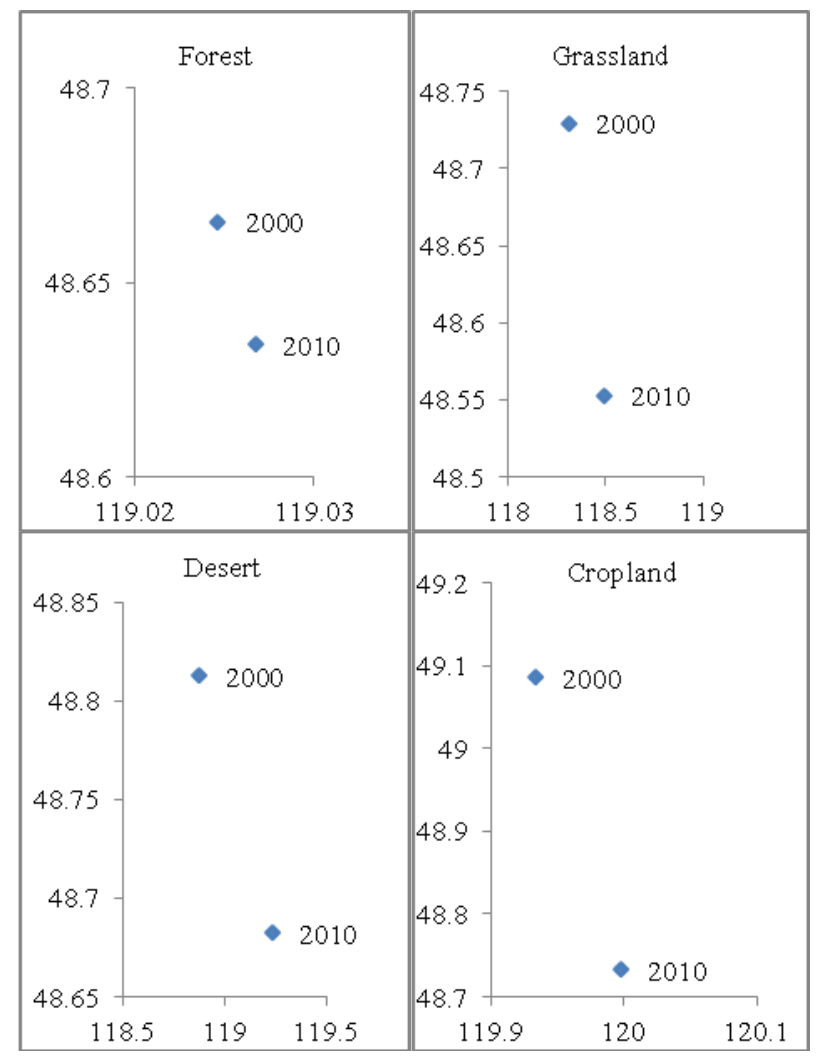

Fig.2. Dynamic changes of centroid from 2000 to 2010.
From the above analysis, the grassland is the dominant landscape type. But, due to the three periods of historical exploitation at $1920 \mathrm{~s}-1930,1950 \mathrm{~s}-1970 \mathrm{~s}$ and $1980 \mathrm{~s}^{[12]}$, the fragmentation of landscape becomes worse and worse. So, the balance between grassland and other landscape components hasn't been reached until now. The diversity and spatial heterogeneity of landscape patterns grow significantly.

Although local residents and governments have been aware of the trend and essential environmental protection strategies have been carried out these years ${ }^{[13]}$, the degradation trend still can't be hold back.

\section{DISCUSSION}

\subsection{Core indices reflecting the change}

Despite the gap between each landscape index above isn't very big, the seven landscape indices analyzed in the present paper still could indicate that landscape patterns of Hulunbuir Grassland have changed obviously in the period of 2000 to 2010.

For example, the grassland landscape was fragmented by roads construction and mining, especially along the road from Hailar to Manzhouli. Moreover, the grassland was converted to cultivated land, forest and construction land in large scale in the recent 22 years, these changes showed the obvious feature of leapfrog and spillover effects ${ }^{[13]}$.

\subsection{Driving factors of landscape patterns}

\subsubsection{Natural factors}

The natural factors affecting changes of grassland landscapes include temperature, precipitation and wind speed. The precipitation of Hulunbuir Grassland, whether in spring or in winter, doesn't decrease nor increase obviously from 1960s. But, the average annual temperature increased by $0.11^{\circ} \mathrm{C} / \mathrm{a}$, while, in spring by $0.15{ }^{\circ} \mathrm{C} / \mathrm{a}$ and $0.19{ }^{\circ} \mathrm{C} / \mathrm{a}$ in winter during 1984-2000 [5]. From 1970's to 1990's, the south line of permafrost has retracted to the northeast from New Barag Right Banner-The North of Buir Lake to Wangong of Old Barag Banner- Nuogunnuori of New Barag Left Banner ${ }^{[14,15]}$ (Fig 3).

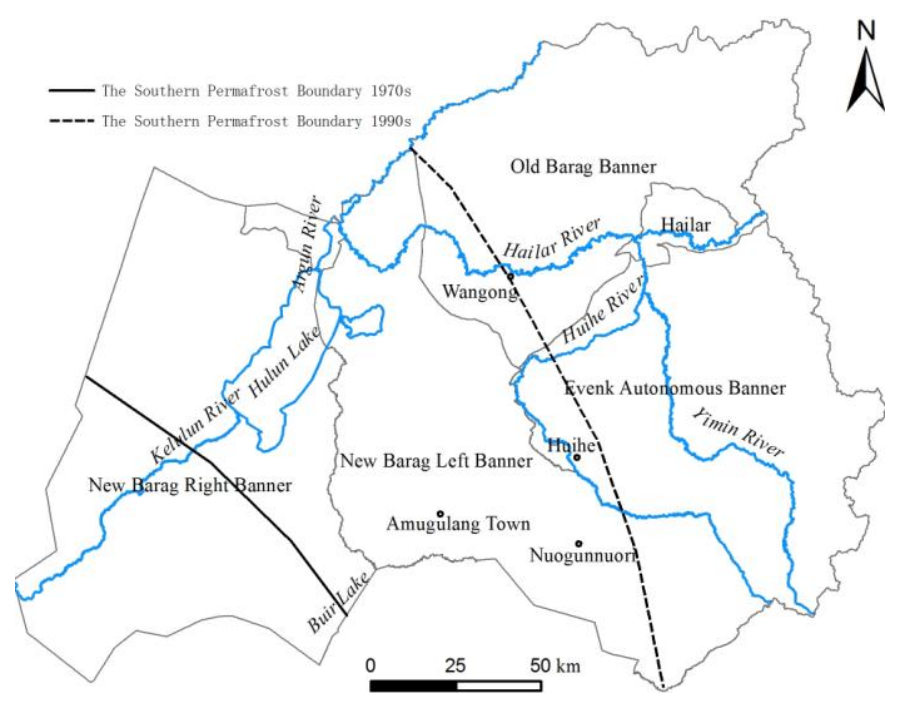

Fig.3. Shift of the southern permafrost boundary ${ }^{[5]}$. 
So, the frozen-thaw process should be taken into account to analyze the driving forces of landscape patterns change in Hulunbuir Grassland. As the permafrost thaws, the surface water infiltrates downward so significantly that many environmental problems happened, such as vegetation degradation, lake reducing and drought of marsh ${ }^{[16]}$. Vice versa, the problems will accelerate the thaw of permafrost and mutually reinforce each other.

\subsubsection{Human activities}

According to the statistics, the population of New Barag Banner and Old Barag Banner, which locates in the main grassland zone, increased by 7.6 times from 13013 (1947) to $99198(2005)^{[5]}$. The sixth census of population shows that the total number has reached to 134858 at 2010, about 10.36 times of the population in 1947 with growth of 1934 person per year. The huge demographic growth causes over grazing, over reclamation, over fuel collection and over use of water resources, as well as industrial, mining and transportation construction, the vegetation degradation can hardly be controlled in short periods of time.

\section{CONCLUSIONS}

During the past decade, the total area of water decreased by $462.59 \mathrm{~km}^{2}$, grassland by $234.71 \mathrm{~km}^{2}$ and forest $146.86 \mathrm{~km}^{2}$, whereas the areas of construction land, desert, cropland and wetland increased by $462.59 \mathrm{~km}^{2}, 189.43 \mathrm{~km}^{2}, 99.33 \mathrm{~km}^{2}$ and $26.74 \mathrm{~km}^{2}$ respectively. The Landscape indices, NP increased by 1161 and PD by 0.02 , while the MPS decreased by 2.24 $\mathrm{km}^{2}$ and LPI by 0.35 . Moreover, the SHDI and SHEI increased by 0.02 and 0.10 . The centroids of grassland, forest, desert and cropland move to the southeast about $39.24 \mathrm{~km}, 30.32 \mathrm{~km}$, $23.80 \mathrm{~km}$ and $3.49 \mathrm{~km}$ respectively. The experimental results can reflect the temporal and spatial change of landscape patterns in Hulunbuir Grassland appropriately, although the difference of measure index isn't so large.

The combination of indices and driving factors including temperature rising, permafrost thawing, huge demographic and economic growth pressures, can explain properly the changing progresses. Due to the historical exploitation, the degradation trend can hardly be hold back, although many environmental protection strategies have been carried out from 2000.

\section{ACKNOWLEDGMENT}

This study was supported by The Key Deployment Project of Chinese Academy of Sciences (NO. KZZD-EW-08-02). We thank the participants involved in the construction of scientific database.

\section{REFERENCES}

[1] Xiulan Wang, "A research on the change of agricultural land use and impact on rural sustainable agricultural development
Hulunbeier Distract based on the remote sensed data", Progress In Geography, Vol.18, No.4,1999, pp.322-329.

[2] Licheng Liu, "Spatial temporal landscape dynamics in the Hulunbeir Forest-steppe Ecotone", Acta Ecologica Sinica, Vol.28, No.10, 2008, pp. 4982- 4991.

[3] Shihai Lv, "Analysis and prediction of landscape pattern changes in Hulunbeir Forest-Steppe Ecotone using Markov Model", Research of Environmental Sciences, Vol.21, No.4, 2008, pp. 63-68.

[4] Hongbin Zhang, "Analysis of dynamic spatial temporal changes of landscape patterns in Hulunber meadow steppes-taking Hai laer and surrounding areas as an example", Acta Prat Aculturae Sinica, Vo 1.18, No.1, 2009, pp. 134-143.

[5] Jian Guo, "Dynamic variation of aeolian desertified land in Hulun Buir Grassland", Journal of Desert Research, Vol.29, No.3, 2009, pp. 397-403.

[6] Feng Zhang, "Study on quantitative method of spatial and temporal dynamic monitoring of vegetation cover in Hulun Buir Grassland", Journal of Natural Resources, Vol.25, No10, 2010, pp. $1698-1708$

[7] Geli Zhang, "Responses of grassland vegetation to climatic variations on different temporal scales in Hulun Buir Grassland in the past 30 years", J. Geogr. Sci, Vol.21, No.4, 2011, pp. 634-650.

[8] Kezhen Guo, Theory and Techniques of Ecological Water Conservancy in Pastoral Area, Hohhot: Inner Mongolia People's Publish House, 2004.

[9] Wenhui Wang, Climate in Inner Mongolia, Beijing: Meteorology Press, 1990.

[10] Jianguo Wu, Landscape Ecology-Pattern, Process, Scale and Hierarchy, Beijing: Higher Education Press, 2000, pp. 99-109.

[11] Jianmin Feng, "Study on the actuality and historical evolution of desertification in the Hulunbeir Grasslands", Arid Land Geography, Vol. 27, No.3, 2004, pp. 356-360.

[12] Altan MunkhDalai Zhang, "Analysis on the current status and the changes of land use in Hulunbuir, Inner Mongolia", China Land Science, Vol.25, No11, 2011, pp. 43-48.

[13] Lijian Zhang, "A consideration on the comprehensive demonstration area of ecological protection and construction in Hulunbeier Grassland", Chinese Journal of Grassland, Vol.132, No.15, 2010, pp. 1-4.

[14] Wei Z, Jin H J, Zhang J M, et al, "Prediction of permafrost changes in Northeastern China under a changing climate", Sci China Earth Sci, Vol.54, No.6, 2011, pp. 924-935.

[15] Guowei Lu, "The geographic boundary of permafrost in the northeast of China", Journal of Glaciology and Geocryology, Vol.15, No.2, 1993, pp. 214-217.

[16] Xian Xue, "Development and cause of aeolian desertification in alpine region", Journal of Desert Research, Vol.27, No.5, 2007, pp. 725-731. 